\section{Editorial: On IRIE Vol. 11}

IRIE, designed as a pure online journal, new issues announced by email, downloadable and fully readable as e-paper - in 2003 the founding editors really thought they have created a zero waste journal. But now we learned that much more has to be taken into account if one really wants to calculate the ecological bottom line of IRIE, including the electricity consumed by hosting the journal as well as reading it and above all the construction and disposal of the hardware engaged. Ultimately this expansion of the scope of our respective self assessment leads to an expansion of the scope of information ethics itself.

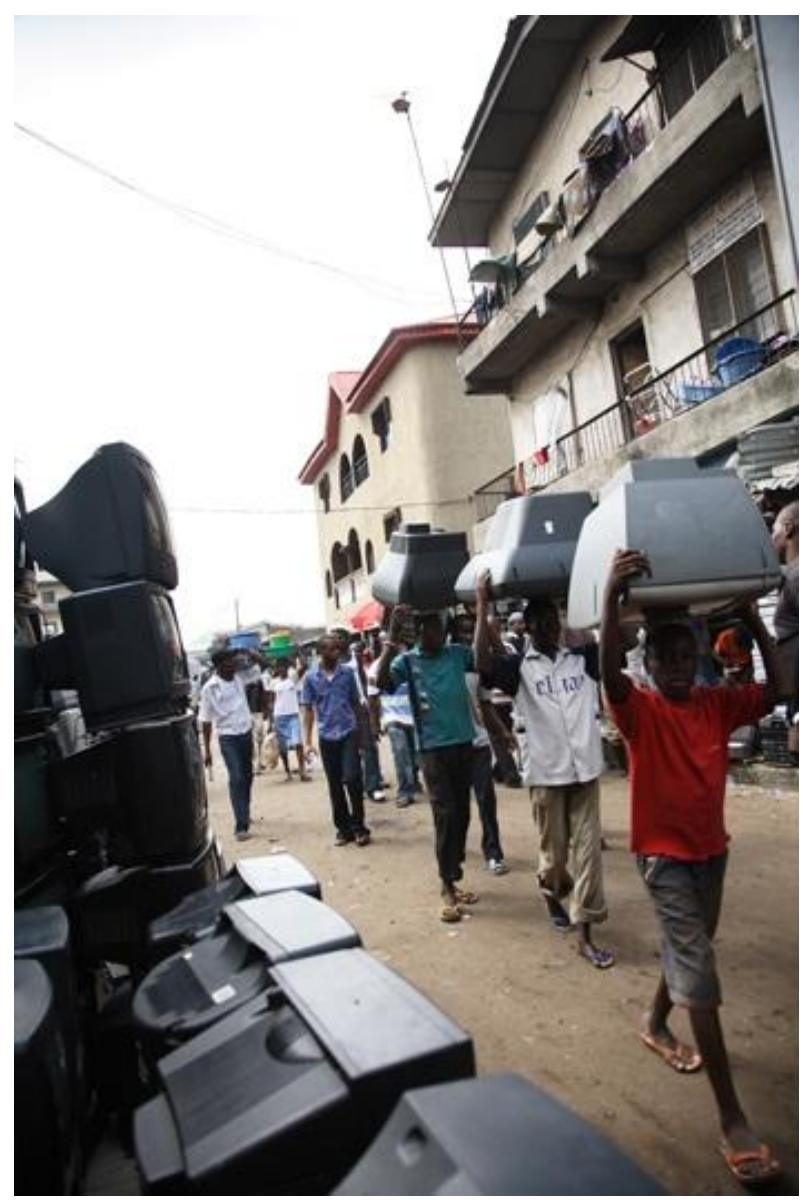

Figure 1: Monitor trade - Lagos, Nigeria - (c) Kristian Buus, (http://kristianbuus.com), Greenpeace Int

With this issue, IRIE - dedicated to the development of information ethics as a reflexive practice and conceptual horizon - aims to engage itself with the broad range of materials involved in the very acts and processes of communication, information, and knowledge production. This includes, but is not limited to, the instruments we employ, use, and discard in ever-shorter cycles of consumption, outpacing our efforts to develop appropriate mechanisms of disposal and recycling: from old television sets to LCD and plasma displays, from old disk drives to flash cards and RFID chips.

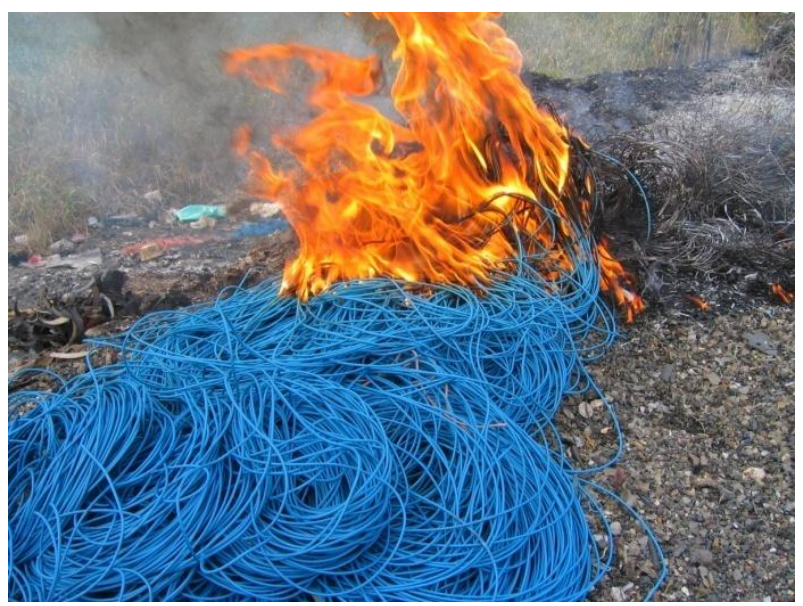

Figure 2: E-waste open burning in China (c) EMPA (http://ewasteguide.info)

Used locally, but designed, produced, and discarded across the world, the usage of these instruments - things - raises a lot of questions whose technical and political implications are increasingly being explored in an emerging regulatory regime, but whose info-ethical dimensions deserve greater attention as they require us to revisit cherished assumptions regarding the scope and desirability of information-societal developments as we know them.

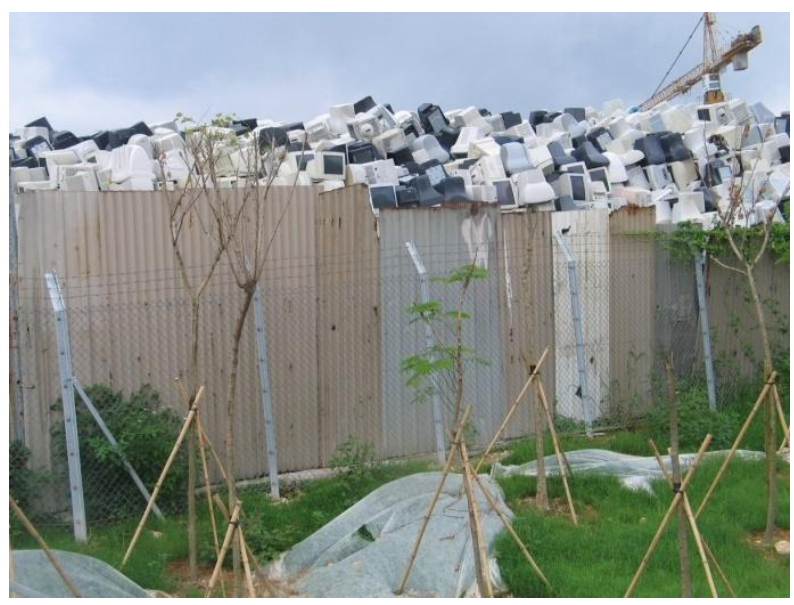

Figure 3: Monitor (CRT) Storage - Hong Kong's New Territories area, (C) Basel Action Network (BAN) 2009, (http://www.ban.org)

The contributions to this issue offer the concept of network ecologies as a way to open info-ethical reflection to geophilosophical perspectives (Zehle), revisit the history of electronics activism and regulation (Smith, Fonseca and de Carvalho Matie- 
lo), reflect on the need to rethink waste or debris as resource for socio-technological innovation and survival (Vallauri, Renno), attend to the ecological impact of networks of distributed labor (Miller) and the biopolitical dimension of the simultaneous governance of waste and work (Rossiter), remind us of the material embeddedness of all infoethical, geophilosophical reflection to encourage the embrace of an ethics of passage (Carter), and insist on the need to take abundance rather than scarcity as point of departure and reference and develop holistic approaches attentive to their complex relationship (Verzola).

Together, the authors offer themselves as interlocutors in info-ethical exchanges, some directly, some from within different (perhaps even incommensurable) analytical frameworks, recalling that acts of translation are always already involved in any attempt of ethical reflection.

Sincerely,

Matthias Feilhauer, Soenke Zehle and the editors

Please do not print this issue unless you really need to ;-) 